\title{
Distinct temporalities in the breast cancer disease process*
}

\author{
DIFERENTES TEMPORALIDADES NO ADOECIMENTO POR CÂNCER DE MAMA \\ LAS DIFERENTES PERCEPCIONES DEL TIEMPO EN LA ENFERMIDAD POR CÁNCER \\ DE MAMA
}

\author{
Janderléia Valéria Dolina', Roseney Bellato², Laura Filomena Santos de Araújo³
}

\begin{abstract}
Comprehensive approach study aimed understanding the reflections and contrasts between personal time and medical therapy protocol time in the life of a young woman with breast cancer. Addressed as a situational study and grounded in Beth's life story about getting sick and dying of cancer at age 34, the study's data collection process employed interviews, observation and medical record analysis. The construction of the analytic-synthetic box based on the chronology of Beth's clinical progression, treatment phases and temporal perception of occurrences enabled us to point out a linear medical therapy protocol time identified by the diagnosis and treatment sequencing process. On the other hand, Beth's experienced time was marked by simultaneous and non-linear events that generated suffering resulting from the disease. Such comprehension highlights the need for healthcare professionals to take into account the time experienced by the patient, thus providing an indispensable cancer therapeutic protocol with a personal character.
\end{abstract}

\section{DESCRIPTORS}

Qualitative research

Cancer

Life changing event

Health care

\section{RESUMO}

Estudo de abordagem compreensiva, objetivou compreender os reflexos e contrastes entre o tempo experiencial e o tempo protocolar da terapêutica, na vivência de mulher jovem com câncer de mama. Conformando-se como estudo de situação, baseado na História de Vida de Beth, que adoeceu e morreu de câncer aos 34 anos, empregamos entrevista, observação e análise do prontuário na recolha dos dados. A construção de quadro analítico-sintético, com base na cronologia da progressão clínica e fases do tratamento e a percepção temporal dos acontecimentos por Beth, possibilitou depreender que o tempo protocolar da terapêutica mostra-se linear, marcado pelo sequenciamento do diagnóstico e tratamento; já o tempo experiencial é marcado pela simultaneidade e não linearidade de acontecimentos mobilizadores de intenso sofrimento que o câncer produziu na vida de Beth. Tal compreensão afirma a necessidade dos profissionais de saúde considerarem o tempo vivido pela pessoa, conferindo pessoalidade à indispensável terapêutica protocolar do câncer.

\section{DESCRITORES \\ Pequisa qualitativa \\ Câncer \\ Eventos que modificam a vida \\ Cuidados à saúde}

\section{RESUMEN}

Estudio objetivo conocer los contrastes entre el tiempo de la experiencia y el tiempo de tratamiento en la enfermedad por cáncer de mama. És basado en la historia de vida de Beth, que cayó enferma y murió de cáncer a los 34 años, uso entrevista, observación y análisis de los registros medicos para tener datos. La construcción de la imagen analítico y sintético basado en la cronología y progresión del tratamiento clínico y la percepción temporal por Beth, permitió concluir que el tiempo del protocolo se muestra lineal, marcado por la secuenciación del diagnóstico y tratamiento; mientra que el tiempo experiencial está marcado por simultaneidad y no linealidad de los eventos de sufrimiento que el cáncer produce en la vida de Beth. Tal entendimiento afirma la necesidad de considerar el significado del tiempo para la persona enferma, para que tenga un cuidado personal, esencial en la terapia del cáncer.

*Unpublished article originated in the master's degree dissertation, "Experience of a young woman and her family in the sickening and dying process from breast cancer." The study is part of the matrix research called "Healthcare and justice institutions as mediators in health parental rights implementation: analysis of therapeutic itineraries of people/families at the UHS/MT," and was carried out within the scope of the "Nursing, Health and Citizenship Research Group" (GPESC) of the Nursing College of the Federal University of Mato Grosso (FAEN/UFMT). The study was financed as a scientific initiation and master's degree grants. No conflict of interest was found. ${ }^{1}$ Nurse; Master's in Nursing, member of the Nursing, Health and Citizenship Research Group (GPESC). Cuiabá, Brasil. ${ }^{2}$ Nurse; Doctorate in Nursing; professor at the Nursing College of the Federal University of Mato Grosso (FAEN/UFMT), member of the GPESC, Cuiabá, Brazil. ${ }^{3}$ Nurse; Doctor in Nursing, professor at the FAEN/UFMT, GPESC leader, Cuiabá, Brazil. 


\section{INTRODUCTION}

Breast cancer is a type of malign neoplasia that mainly affects female populations and whose incidence rates increase every year as a result of changes in lifestyle and wider exposure to risk factors. In Brazil, estimates point to 570,000 new breast cancer cases in 2014 ${ }^{(1)}$; however, women still face difficulties regarding early diagnosis and efficacy of treatments. It should be highlighted that the majority of women affected by breast cancer experiences the disease and/or related treatments for years. Treatment may include surgery to eliminate the tumoral mass, chemotherapy, radiotherapy, and in some cases, several years-long hormone and biological therapies. Following the period of treatment, medical follow-up is prescribed, encompassing periodic exams for another five years, in such a way that the appearance of metastases or recurrence of the disease may be prevented ${ }^{(2)}$. Recurrence of the disease implies a new therapeutic plan and may call for surgery, chemotherapy and radiotherapy, as long as they are necessary.

The duration of the disease and related treatments are sanctioned by custom in oncology, being dependent upon genetic predisposition, type of cancer, health status at the time of diagnosis, and organic response to treatment, among other factors. As each organism responds in a different way, the proposition of specific therapeutic plans and individualized protocols ${ }^{(2)}$ should always be required. Such individualization should be a prerequisite for both the procedures and drugs to be used, and the temporal period of each therapeutic phase.

Therefore, "therapeutic protocol time" follows linearchronological temporal logic, based on a parceled, sequenced therapeutic process. The medical approach must be based on a series of interventions that complies with the organic-pathologic response.

Nonetheless, a patient experiencing the cancer disease process is struck by an avalanche of information and pressed to make practical decisions, among them countless imposed pilgrimages for treating the disease, the need to cope with the reality of potential stigmas, uncertainties concerning effectiveness of treatments, and fear of recurrence, eventual mutilation and the concrete possibility of dying in the process ${ }^{(3)}$. This myriad of staggering occurrences generates intense suffering, allied with the uncertainty of the treatment results and the continuation of life itself.

As a matter of fact, the time experienced by patients follows its own temporal logic. Hence, the "experimental temporality" born up by patients with cancer needs to be apprehended in its intrinsic - variable, unstable, uncertain - logic, thus taking into account the way each person perceives and makes sense of experienced time in the present, as well as how they combine present issues with past events and future plans.
Such temporality is part of an intricate network of simultaneous striking occurrences based on which patients keep on signifying their lives, now on distinct grounds. The temporality of experienced time is estranged from sequenced chronologic time. It runs in a different mode and is based on reverberations of experiences in which past, present and future are ordained in spiral movements ${ }^{(3)}$.

Healthcare practices demand understanding the meanings assigned by ill persons to their temporal experience of disease and treatment processes, in such a way that professionals are able to more effectively support patients in such painful processes with effective care. This understanding is shown to be more intense when the cancer is deemed to be in chronic status, evidencing the conditions under which patients and their families should be cared for. Chronic situations require professionals to comprehend how people experience their own disease process, as well as the events that insert them into either broader or narrower vulnerability circuits, in such a way that professionals are able to get closer to the "best care" people expect to receive ${ }^{(4)}$.

The present study addresses Beth's disease, treatment and dying process. The young woman received breast cancer treatment for five years. This experience, as narrated by Beth herself in a quite intense way, dramatically drew our attention to how she reported "the times" of the breast cancer progression and how she experienced the treatment to which she was submitted. Her reports contradict the time of the treatment protocol plan for breast cancer offered to her at the healthcare service. As we, as researchers, were aware of the types of organization and sequencing of the different treatment protocols for breast cancer, Beth's reports disturbed us and stimulated us to transform them into the focus of the present study.

As such, we primarily aimed at understanding the reflections and contrasts between the temporal experience and the time of the protocol therapy in the life of a young woman with breast cancer.

\section{METHOD}

This qualitative research with a comprehensive approach stands out as a "situational study,"(3) as it addresses understanding of what goes on in the private context of the ill person and her family. In this microreality, peculiar traits regarding the relationship among the various organized patterns built during their lives produce specific standardized thoughts about the disease and caring experience.

The study is based on a master's dissertation that sought to "comprehend the experience of a young woman 
and her family regarding the disease and dying processes caused by breast cancer".

The participants in the study were Beth, a 34-year-old woman diagnosed with breast cancer at 29, and her family, composed of Beatriz and Bruna, her adolescent daughters, and Dona Carlota, her mother. Beth was contacted at the reference oncologic institution, located in the State of Mato Grosso, Brazil, where she was being treated. Inclusion criteria were: being a patient with a diagnosis of advanced breast cancer with no medical prognosis of cure; being able to express herself verbally; and formally agreeing to take part in the study.

In the data collection process, the life history (LH) approach allowed us to understand Beth's experiences and the meanings she assigned to them ${ }^{(5,6)}$. As expected from such a methodological approach, deep understanding of the situation was enabled by the establishment of a trustful relationship between the researchers and the patient, built throughout nine meetings that occurred between October 2011 and May 2012.

It was agreed that this type of study should be based on:

[...] the sharing of emotions that makes possible the densification of the life history and the reach of several different degrees of depth and involvement between the researcher and the subject of the research, thus turning the telling of the story and the listening processes into a mutual relationship of care and human $\operatorname{growth}^{(7)}$.

The guiding question for this study was: "Tell us about your life, disease and care experience." The telling of the story was shown to be an active work of Beth's memories, full of emotions and feelings. Subsequent questions were created aimed at broadening the understanding of relevant dimensions of her experience. A few interviews were recorded; other meetings, due to Beth's fragile health status and her great difficulty with verbal expression, were reported in detail. The observation process was also employed in each meeting, later generating a thorough report of gestures, attitudes, feelings, silences and the impressions of the researchers.

The study's data collection process also used information entered into Beth's medical records by the healthcare institution that performed the treatment. Access to the documents was formally authorized. The medical records provided some data concerning the various diagnostic and therapeutic procedures Beth was submitted to throughout five years, beginning with the discovery of the cancer in 2006 and ending with her death on December 8, 2011.

The fully transcribed material resulting from recorded meetings, together with the observations carried out and the transcription of medical record input, were entered into the "research diary"(5) in a Microsoft Word file, totaling 86 pages, which constituted our analysis corpus.

The analysis consisted of careful and accurate reading of all the material. The contrast between the times set out by Beth and the times of the breast cancer protocol intrigued us. Such disturbances allowed us to observe specific meaning units, which in a continuous and artisanal filtering process enabled us to define the thematic axis named "The treatment time and the time experienced by a young woman with breast cancer," displayed in the box and discussed in the present study.

Ethical norms were fully complied with and the matrix research that generated this study was approved by the Research Ethics Committee of the Julio Muller University Hospital, under protocol number 671/CEPHUJM/09.

\section{RESULTS}

Comprehension of Beth's narratives gave evidence of the non-linearity of the time experienced by her, showing an "affective" construction of such time and providing it with a peculiar chaining process. Analysis of the medical reports also pointed out a sequenced logic of several diagnostic-therapeutic interventions she underwent. Both of these logics were synthetically organized in a descriptive-analytical box (Box 1), aimed at providing evidence of the diversity with which a similar reality can be displayed, meaning the therapeutic protocol and Beth's experienced time.

The sequenced columns in the box show: the chronology of the event inserted into Beth's medical records, expressed in year, month and/or day; the performed intervention denoting the clinical progression of the cancer and the treatment phases; and finally the temporal perception of these occurrences highlighted in Beth's narratives. Such narrated fragments gave proof of the intensity of the suffering felt by the young woman. These fragments are organized in sequence, by ordinal numbers and excerpts from the narratives - letters "a" and "b," respectively - in a way that pinpoints them in the presentation of the work.

In order to more strongly highlight the intensity of what we have called "different temporalities of the experience," we preserved Beth's way of talking about the events when transcribing her narratives, emphasizing the distinct voice intonation whenever she spoke about certain terms or expressions regarding her own experiences, by which she seemed especially willing to underline her experiences, mainly shown by slowdowns or accelerations in the narrative, with more or less intensity. 
Box 1 - Therapeutic protocol time and beth's experienced time - cuiabá - 2014.

\begin{tabular}{|c|c|c|}
\hline Chronology & $\begin{array}{l}\text { Clinical progression and treatment } \\
\text { phases }\end{array}$ & Beth's temporal perception of the events \\
\hline \multirow[t]{3}{*}{ May/2006 } & 1a: breast cancer diagnosis. & $\begin{array}{l}\text { 1b: [...] then it evolved, suddenly there was that lump that started growing and } \\
\text { growing... It took SOOOOOOOO long [exam results]... they asked for an ultrasound. } \\
\text { Then, all of a sudden, it was diagnosed [...] it is complicated, you know you have a } \\
\text { disease like this. The first thing you can think of is: "Gee, you're gonna die". }\end{array}$ \\
\hline & $\begin{array}{l}\text { 2a: four chemotherapy rounds aimed at } \\
\text { reducing tumoral margins. }\end{array}$ & $\begin{array}{l}\text { 2b: Then, it all started. First, it was the chemo [...] But what got me mad was not } \\
\text { the cancer itself, but the treatment, you know. It is quite aggressive... First chemos } \\
\text { went on and after } 14 \text { days I was already hairless. I vomited for } 15 \text { days on my bed. }\end{array}$ \\
\hline & $\begin{array}{l}\text { 3a: conservative surgery for partial } \\
\text { removal of the breast. }\end{array}$ & $\mathbf{3 b}$ :[...] then, there was the surgery. I underwent the surgery, the first surgery. \\
\hline \multirow[t]{3}{*}{ August/2007 } & $\begin{array}{l}\text { 4a: six doses of adjuvant chemotherapy } \\
\text { associated with radiotherapy. }\end{array}$ & $\mathbf{4 b}:[\ldots]$ after that, I was stuck in chemotherapy only. \\
\hline & $\begin{array}{l}\text { 5a: axillary lymph node biopsy to } \\
\text { confirm local-regional recurrence. }\end{array}$ & $\begin{array}{l}\text { 5b: After } 30 \text { days, the tumor showed up again. }[\ldots] \text { it was } 7,8 \mathrm{~cm} \text { big, and it grew } \\
\text { very fast. The type of tumor I have grows, grows very quickly, very quickly indeed } \\
\text { [emphasis]. }\end{array}$ \\
\hline & $\begin{array}{l}\text { 6a: radical mastectomy of the left } \\
\text { breast. }\end{array}$ & $\begin{array}{l}\text { 6b: Then, I was operated on again. And once again } 30 \text { days later.. I had four in } \\
\text { a row, you know. (referring to the surgeries). And, in the last one, the doctor went } \\
\text { up to the bone, quite radical indeed. }\end{array}$ \\
\hline September/2008 & 7a: six chemotherapy doses. & $\begin{array}{l}7 \mathbf{b} \text { : I had several chemotherapies, several sessions. Then, the medication was } \\
\text { replaced, they saw that the tumor did not respond accordingly, then it was } \\
\text { replaced for another again. They kept on replacing the drugs. }\end{array}$ \\
\hline September/2009 & $\begin{array}{l}\text { 8a: evolution to pleura metastasis, six } \\
\text { chemotherapy rounds. }\end{array}$ & $\begin{array}{l}\mathbf{8 b} \text { : [...] I can't stand it, I can't even walk from here to there [crying], someone has } \\
\text { to back me up, you understand that? }\end{array}$ \\
\hline $2009-2011$ & $\begin{array}{l}\text { 9a: admitted three times in the } \\
\text { Intensive Care Unit, pleurodesis in two } \\
\text { of them. }\end{array}$ & $\begin{array}{l}\text { 9b: [...] I took } 30 \text { mg of methadone, then, from } 30 \text { it was increased to } 90 \text { mg. I got } \\
\text { sort of nuts, I even did things I could not remember doing, I was awake and I was } \\
\text { not aware of it, the next day I could not remember anything. Now, my body has } \\
\text { gotten used to it, those effects are gone. But the pain is back. I feel terrible pain, } \\
\text { even before the time for the next medicine comes, the pain is already killing me. }\end{array}$ \\
\hline September/2011 & 10a: admittance, new pleurodesis. & $\begin{array}{l}\text { 10b: [...] it was placed too high [the drain] and it didn't work out. It started } \\
\text { hurting and hurting, so terrible was the pain that I almost died. It was there for } \\
\text { five days. }\end{array}$ \\
\hline October/2011 & $\begin{array}{l}\text { 11a: Beth was required to return to the } \\
\text { treatment, now deemed to be beyond } \\
\text { any possibility of being healed. Search } \\
\text { for another healthcare professional. }\end{array}$ & $\begin{array}{l}\text { 11b: Then, doc Jair didn't want to deal with me anymore. "- Oh, doc Jair, while } \\
\text { there is life, there is hope. Won't you even prescribe another chemo?" - "No, I won't } \\
\text { prescribe another chemo" [...] Then, I was seen by doc Luis, a chemotherapist, such } \\
\text { as doc Jair's specialty, you know. I had to hunt somebody else down. Then I went } \\
\text { there, he said that for the moment he would not prescribe chemo because I was that } \\
\text { way, you know [referring to the fatigue, respiratory distress and pain]. }\end{array}$ \\
\hline Dec 6, 2011 & $\begin{array}{l}\text { 12a: admittance due to intense } \\
\text { respiratory difficulty. }\end{array}$ & 12b: "What is going on with me?" \\
\hline Dec 8, 2011 & $\begin{array}{l}\text { 13a: cardiac arrest, death reported at } \\
\text { 6:30 a.m. }\end{array}$ & 13b: Text from Beatriz - "My mother is dead". \\
\hline
\end{tabular}

In order to better organize and clarify the ideas presented here, we initially chose to thoroughly describe the box, since it presents different temporalities compared with those apprehended by our interpretation of time. Later on, we will present the debates with the authors, which will enable us to broaden such interpretations.

We contacted Beth in October 2011. At that time she was 34 years old. At 29, she realized she had a lump in the left breast (box 1, 1b), triggering the search for diagnosis and undergoing a number of exams. In her perception, it took a very long time for doctors to provide her with a response. When describing the search, Beth employed a peculiar speed in the narrative, repeating words in order to highlight the continuous and accelerated growth of the tumor. Sometimes, she sort of chanted the narration of the story, expressing the long time between the discovery of the lump and the realization of the exam and its result.

In May 2006, Beth was finally given the breast cancer 
diagnosis (box 1, 1a). Her medical record shows a triple negative, stage III tumor. In other words, a locally advanced tumoral mass larger than five centimeters. This type of breast cancer attacks younger women prior to menopause, and is generally more aggressive and shows the worst prognosis. It corresponds to nearly $15 \%$ of all invasive breast cancers and does not respond to treatments employing drugs directed to specific molecular targets or hormone therapies ${ }^{(8)}$.

When Beth received her diagnosis, she thought it meant a death sentence; it was very hard to accept. When she talked to us about this phase, after some minutes of silence, she resumed her story as if she had taken a breath, and said, "Then, it all started..." (box 1, 2b). After that, she revealed a tsunami of memories related to her pilgrimages in search of therapeutic procedures. These events took place during an undefined temporal period; but, for her, they seemed to be amassed in a short lapse of time.

In the same year (2006), Beth started receiving chemotherapy (box 1, 2a) to reduce tumoral bulk prior to the surgical procedure. The first round lasted for approximately three months, in four chemotherapy doses interspersed at periods of 21 days. The period encompassed between the beginning of the treatment and the first conservative surgery to partially remove the left breast is narrated by her as if there were a certain abbreviation of time into few weeks (box $1,2 b$ ). She packed the beginning of the chemotherapy sessions and the performance of the first surgery into only one sentence. On the other hand, when speaking about the side effects of the chemotherapy, she took a long time in the descriptions, highlighting the quick hair loss and the coercive vomiting. In this way, she deems the treatment to be a disease by affirming, "What got me mad is the treatment."

In August 2007, Beth received six more chemotherapy doses interspersed at 21 days; this time, they were associated with radiotherapy (box 1, 4a). After the end of these procedures, and over the six months after the first surgery, Beth's breast cancer had a local-regional recurrence; moreover, new axillary lymph nodes were also detected (box 1, 5a). After the confirmatory biopsy, she underwent a total mastectomy of the left breast in order to excise the tumor along with all correspondent axillary lymph nodes.

The period between the first surgery, the biopsy and the total mastectomy was experienced by Beth as a quite condensed time, given the turmoil and the intensity of her suffering and her pilgrimages in search of treatment. During this period, sequenced and interspersed procedures in the temporal calculation of the specific therapeutic protocol aimed at her type of cancer were, according to Beth's perspective, resignified as being contiguous events; she eliminated intervals and emphasized the cancer itself, with its voracious growth speed. In this way, her narrative employs the repetition of words in order to provide a sequence and an acceleration to her experienced time (box $1,5 b, 6 b$ ).
In this whirlwind of events, Beth realized that she was running after something she could not catch or fighting against something she could not detain, as "the tumor grows, grows very quickly, very quickly indeed." Beth also brought us some allegoric images that gave proof of the striking meanings of her experience, such as, "went up to the bone, quite radical indeed." She employed such terminology in order to highlight how extreme her last surgery had been and especially her understanding of the cancer "embedded in her bones," much more serious than the initial lump.

In September 2008, Beth underwent another chemotherapy treatment, once again divided into six sessions interspersed at 21 days. From her perspective, being submitted to chemotherapy rounds this time meant that the tumor "did not work out." That is why they kept "replacing" the employed drugs (box 1, 7b). She expressed, therefore, that this experience repeatedly brought back her suffering and countless uncertainties.

One year following the last chemotherapy, cancer cells were detected in Beth's lung, and also metastasis in her pleura (box 1,8a), according to what was recorded in her medical report. Once again, she was submitted to six more chemotherapy doses. However, at this stage, three years after the initial diagnosis and after dozens of therapy plans, Beth was weak and debilitated. She also developed a pleural effusion, which made it very difficult for her to breathe, resulting in all-day tiredness and the need for the support of others in order to carry out any activity whatsoever (box 1, 8b).

For over two years, Beth suffered the effects of the pleural effusion and needed to be admitted three times to the Intensive Care Unit for the realization of a pleurodesis, aimed at providing relief to her respiratory difficulty. Additionally, she needed to get used to the side effects of the sedatives employed to minimize the intense pain, such as morphine, which made her feel sleepy during the day and forget things she had done or said (box 1, 9b). Beth expressed her excruciating pain as a "terrible pain" and said that "the pain is killing me" (box 1, 9b), also including the pain resulting from the medical procedures, such as the pleurodesis of September 2011, in which the perception of pain was associated with death itself (box 1, 10b).

In October 2011, her doctor informed her of the impossibility of keeping up the treatment any longer, given her poor general health status (box 1, 11a). Refusing to accept the doctor's prognosis, she looked for another medical professional who, despite not giving her any hope, at least did not abandon her for good, stating that he would wait for a time in order to try other alternatives (box 1, 11b). Time, at last, had presented itself as an ally of her hope, although no concrete actions could be taken.

On December 6, 2011, Beth was admitted for the last time due to intense respiratory distress (box $1,12 a$ ). One 
day after her admission, now crushed, exhausted and extremely anxious, she talked to us once again and expressed her feelings regarding her health status. We realized, for the first time, that she was really willing to know what was happening, as she repeated quite a few times the same question, "What is going on with me?" (box 1, 12b). This time, we could give Beth the answer she was so desperately waiting for in a calm, serene and supportive way. Our conversation following the answer to her question took nearly three hours. In it, few words were necessary, showing that time could finally go by in a sweeter way for her. On the morning of the next day, December 8th, 2011, Beth had a cardiac arrest and died (box 1, 12a). The information was texted to us by her daughter Beatriz (box 1, 13b).

It was the end of a short life, although a long and intense one, as Beth had so many stories and experiences to share. As her death drew nearer, her experienced moments of the past were levered to another dimension and started having different meanings and times, as she resignified each process by either broadening or concentrating it amidst much suffering, thus making each moment unique.

\section{DISCUSSION}

The synthetic box showing the chronology of the cancer and highlighting the disease's clinical advancement and the stages of treatment, as well as contrasting the disease from Beth's perspective in experiencing the disease and treatment process, enabled us to grant visibility to dimensions otherwise unknown to the researchers. The meanings assigned to time by Beth, as if the pains, pilgrimages and intense reactions to the countless therapies and procedures had occurred in a short period of time, although the treatment process took five long years, was clearly evidenced. Obviously, intensely experienced suffering seemed to abbreviate time, as it substantially spread out and filled Beth's life, being experienced by her as a "condensed temporal period."

In order to comprehend Beth's perception concerning her disease and dying process, as well as the evolving phases of the cancer and the sequence of the therapeutic efforts toward her healing, we find support in the French philosopher Gaston Bachelard, as he offers us the idea of "sensitive time". That concept seems to be the closest to Beth's narratives. For Bachelard, away from the homogeneity of chronologic time, subjective apprehension of sensitive time is a result of its differentiated extensions, as an extension of time can only be identified when an agent judges it to be long or short. Even more,

[...] events, therefore, concurrently satisfy and frustrate our waiting, justify the continuity of the empty rational location and impose the discontinuity of empirical memories [...] At contradicting us, events are deeply fixed on our being ${ }^{(9)}$.

As previously highlighted, the temporal period of the cancer and its treatment - here called "therapy protocol time" - is widely studied, thus making its "drug doses" medication, radiation or surgical procedures - sanctioned by custom. Time, therefore, is calculated under a logic that is external to the patient. If treatment is "individualized," it is individualized only concerning the disease, not in relation to the patient's life.

However, despite the diversity of meanings observed in experienced time, it is primarily based upon the cancer disease and treatment process. The logic of the time experienced by patients in the turmoil of mobilizing events that generate so much suffering certainly misshapes and reshapes time in other nonlinear dimensions.

When exhibiting the metaphors of cancer, the author ${ }^{(10)}$ calls it "a standard euphemism," as it is characterized as a long-term disease that acts slowly and treacherously. Nevertheless, for Beth, this time was experienced as a short period. The intensity of the cancer's growth and the voracity of its manifestations, allied with its speed, were expressed in a quite emphatic way, a trait that provided the cancer with a life in itself. Suffering certainly overflowed in Beth's life, sharpening her perceptions about abbreviated time adjusted by "intensity of experienced suffering." Hence, it can be understood that "[...] in temporal frames, the being alternatively loses and wins; the conscience is either realized or dissolved in it. It is impossible, therefore, to experience time being totally rooted in the present"(9).

Bearing such logic in mind, Beth's five years of treatment were so intense and painful that she related to them as a whirlwind of events, emphasizing in her own temporality and under an affective logic of time the recurrence of some resignified and remembered procedures. Or, in other words, the logic of an event that so deeply affected her and pervaded her memories. Hence, although her story was narrated to us in the present, she recalled painful experiences from the past.

Thus, we understand that the plurality of contradictory events may constitute simultaneities that are ordained by a proper internal logic ${ }^{(9)}$; in this logic, instead of running, time now flows out. And although the time of evolution of the cancer and its treatment are more expanded, Beth's perception of the abbreviation of time is a result of the direct connections between the disease and the hardships she endured in her life.

By contrast, the objective time of the cancer treatment process produces a temporal map grounded on the "protocol" within which "a therapeutic plan" must be rigorously and sequentially followed up, established in days and/or weeks, so that its efficacy is guaranteed. In the case of unsatisfactory results, another sequencing process is triggered. However, months, days and hours are not merely mathematical temporal units, but stages of intense and sensitive experiences. In this way, "the affective 
character of the duration, the joy or the pain of being, is a result of the proportion or disproportion of hours in life used either as thinking hours or sympathy hours"(9).

By narrating her experience with her cancer, Beth told us about her living in a broader sense; part of her experience was the disease and dying process as a concrete possibility. Hence, to live and die were perceived by her as temporal perceptions in steady confrontation; if following the therapeutic protocol meant getting away from death, it also promoted another way of living, calculated by external time that should be internalized. And Beth did it with her own logic, assigning distinct meanings to each phase of the protocol, in the same measure as the suffering she felt. This sensitive time experience leads us to understand that:

[...] consciousness of time, for us, is always a consciousness of how we use the moments, it is always active, never passive. In a nutshell, the consciousness of our duration is the consciousness of a progress of our most inner being, be it an effective, imitated or simply dreamed of progress ${ }^{(11)}$.

Although Beth's submission to the therapeutic protocol was passively experienced, that is, based on the protocol defined by the healthcare professionals in accordance with the specificity of her cancer and her response to each proposed plan, she experienced the protocol in a quite active way by intensely acting and reacting to the effects and suffering the disease brought to her. Therefore, it was within the scope of the effects and consequent actions and reactions that she set out the calculations of her experienced time. Within such logic, and only within it, we are able to comprehend her narratives, as this was the experience she was actually talking about.

Thus, it is not up to us to judge and/or confront Beth's protocol and experienced time, but to reveal them, each with its own logic, with her disease situation as our background reality. We also count on Ayres to explain what we have been able to apprehend from such experience. That author makes it clear that healthcare professionals need to establish a relationship with the ill person based on care grounds, and not merely on an intervention toward cure:

\footnotetext{
[...] the way we apply and build scientific technologies and knowledge determines boundaries to what we are able to see. [...] If we also assume that all necessary responses toward reaching health are not restricted to the types of questions that can be formulated by the scientific language, then our health care action cannot be bound to the mere employment of technologies. Our technical intervention has to be articulated with other non-technologic
}

aspects. We cannot limit the art of caring for only to the creation and manipulation of objects ${ }^{(12)}$.

In this way, we agree that the professional care of a human being facing her final moments in life stands out as an "attitude-disposition of really and utterly being together with the other, a special care in the person's living, related to the person's living and for the person's living"(7).

\section{CONCLUSIONS}

We initially highlighted the advantageous and sensitive employment of the exhibition resource, by means of the analytical-synthetic box, regarding the times of the evolution of the cancer and the conduct of the therapeutic protocol, as well as Beth's narratives about her experiences. Such a strategy, although at a first glance it may seem to emphasize the confrontation of such temporal periods, showed a comprehensive potential in this study for granting visibility to dimensions that would otherwise not be known. Hence, we were able to highlight the meanings assigned by Beth to time, as if her pains, pilgrimages and intense reactions to the countless therapies and procedures took place in a personal, condensed temporal period, despite the period of five years between the diagnosis and her death.

Such visibility reinforced the understanding that life is neither linear nor lived in a sequenced shape composed of distinct moments. Life is composed of the intertwining of experienced events that are closely connected with each other, even when they are temporally far away from each other, thus reverberating in what we live in the present.

We ratify the need for professionals to take into account the time experienced by each person, based on the intense suffering resulting from the disease and treatment process, thus providing the indispensable therapeutic protocol of cancer with a personal nature. For us, it is crucial that professionals involved in the care process not only aim at the cure, but also allow themselves to be guided by human understanding of the patient's life, which also encompasses the disease and dying process as constituents of life care.

Finally, we strongly recommend the realization of other "situational studies" that can enable professionals to apprehend senses and meanings assigned by people to their disease, treatment and dying process as a result of cancer, pointing out more effective ways of caring for and supporting them in their suffering. 


\section{REFERENCES}

1. Brasil. Ministério da Saúde; Instituto Nacional de Câncer. Estimativa 2014: incidência do câncer no Brasil [Internet]. Rio de Janeiro: INCA; 2012 [cited 2014 mar. 23]. Available from: http://www.inca.gov.br/estimativa/2014/

2. Bonassa EMA, Gato MIR. Terapêutica oncológica para enfermeiros e farmacêuticos. São Paulo: Atheneu; 2012.

3. Dolina JV, Bellato R, Araújo LFS. O adoecer e morrer de muIher jovem com câncer de mama. Ciênc Saúde Coletiva. 2013;18(9):2671-80.

4. Musquim CA. Experiência de cuidado pelo homem na vivência familiar do adoecimento crônico [dissertação]. Mato Grosso: Faculdade de Enfermagem, Universidade Federal de Mato Grosso; 2013.

5. Araújo LFS, Dolina JV, Petean E, Musquim,CA, Bellato, R, Lucietto, GC. Diário de pesquisa e suas potencialidades na pesquisa qualitativa em saúde. Rev. Bras. Pes. Saúde. 2013;15(3):53-61.

6. Bellato R, Araújo LFS, Faria APS, Santos, EJF, Castro, P, Souza, SPS, Maruyama,SAT. A história de vida focal e suas potencialidades na pesquisa em saúde e em enfermagem. Rev Eletr Enf. 2008;10(3):849-856.
7. Dolina JV, Bellato R, Araújo LFS. Research experience with a person going through the process of dying and death. J Palliat Med. 2014;17(2):244-5.

8. Correa BP, Toralles MBP, Abe-Sandes K, Machado, TMB, Bonfim, TF, Meyer, L, Abe-Sandes, C, Nascimento, I. Cancer de mama triplo negativo e sua associação com ancestralidade africana. Rev Ci Med Biol. 2010;9 (Supl 1):3-7.

9. Bachelard G. A dialética da duração. São Paulo: Ática; 1994.

10. Sontag S. Doença como metáfora. São Paulo: Companhia das Letras; 2007.

11. Bachelard G. A intuição do instante. Campinas: Verus; 2010.

12. Ayres JRCM. Cuidado e reconstrução das práticas em saúde. Interface - Comunic., Saúde, Educ. 2004;8(14):73-92. 